\title{
VARIAÇÃO DO PH EM MEIO AQUOSO DE ALGUNS MATERIAIS RESTAURADORES COM FLÚOR NA COMPOSIÇÃO
}

\section{THE PH VARIATION IN AQUEOUS MEDIUM OF SOME TOOTH FILLING MATERIALS WITH FLUORINE IN THEIR COMPOSITION}

\author{
Nadya Galvão Bengtson ${ }^{1 *}$, Márcia Isidoro Freire ${ }^{1}$, \\ Camilla Regina Galvão Bengtson', Antonio Lucindo Bengtson ${ }^{1}$ \\ $1^{*}$ Autor para contato: Universidade Metropolitana de Santos - UNIMES, Faculdade de \\ Odontologia, Santos, SP, Brasil; (13) 3284 4839; e-mail: nadya_galvão@yahoo.com.br \\ Recebido para publicação em 06/05/2005 \\ Aceito para publicação em 04/08/2005
}

\begin{abstract}
RESUMO
O trabalho avaliou o pH do meio aquoso de imersão de alguns materiais restauradores com flúor na composição, sendo três cimentos de ionômero de vidro convencionais (Vidrion R, Ionofil e Ketac Molar), um cimento de ionômero de vidro modificado por resina (Vitremer), dois compômeros (Compoglass e Freedom) e duas resinas compostas (Fill Magic e Charisma F) durante a reação de presa e hidratação (3 min, 4 h, 72 h e 7 dias). Observou-se pela análise de variância que os materiais apresentaram diferença estatística entre os períodos. Foi aplicado teste Tukey $(1,084)$ para mostrar essas diferenças. Vidrion R, Ionofil, Ketac Molar e Vitremer, não mostraram diferenças significativas entre si, porém foram significantes nos períodos de 3 minutos e 4 horas quando comparados com os outros materiais. Após 4 horas de hidratação, Compoglass provocou uma marcante queda de $\mathrm{pH}$, mantendo-se em queda nos demais períodos. Freedom teve redução com manutenção do pH e as resinas Fill Magic, Charisma F queda do $\mathrm{pH}$, mas todos não significantes em todos os períodos.
\end{abstract}

Palavras-chave: flúor, materiais restauradores, $\mathrm{pH}$

\begin{abstract}
This study evaluated the $\mathrm{pH}$ of an aqueous immersion medium in some tooth filling materials that have fluorine in their composition. Eight materials were studied: three conventional glass ionomer cements (Vidrion R, Ionofil and Ketac Molar), one resin modified glass ionomer cement (Vitremer), two compomers (Compoglass and Freedom) and two composite resins (Fill Magic and Charisma
\end{abstract}


F). The $\mathrm{pH}$ was measured during the setting and hydration reaction, after 3 minutes, 4 hours, 72 hours and 7 days. It was seen through variance analysis that the materials presented statistical differences between the observation times; the Tukey test (1.084) was applied to show these differences. Vidrion R, Ionofil, Ketac Molar and Vitremer did not show significant differences among each other, but were significantly different from the other materials at the times of 3 minutes and 4 hours. After 4 hours of hydration, Compoglass had significant decrease in the $\mathrm{pH}$ that was maintained at the subsequent observation times. In Freedom there was a reduction in $\mathrm{pH}$ that was maintained, and in the resins Fill Magic, Charisma $\mathrm{F}$ there was also a reduction in $\mathrm{pH}$, but none of these were significant at any of the observation times.

Key words: fluoride, restorative materials, $\mathrm{pH}$

\section{Introdução}

A liberação de flúor de materiais restauradores mudou o comportamento clínico profissional frente aos preparos cavitários no controle da progressão da doença cárie. Embora a maior liberação deste halogênio seja obtida com os cimentos de ionômero de vidro (Swartz et al., 1984; Forss e Seppã, 1990; Forsten, 1991; Carvalho e Cury, 1999), estes sofreram modificações pela incorporação de resina para atender necessidades clínicas individuais, melhorando suas propriedades físicas, resistência e longevidade. Assim, a partir das boas qualidades físico-químicas e bio-ativas dos cimentos de ionômero de vidro, vários materiais odontológicos surgiram no mercado além dos cimentos de ionômeros de vidro modificados por resina, como as resinas compostas com flúor e as modificadas por poliácidos. Tais materiais por apresentar na sua composição íon flúor que ao ser liberado participa da ação físico-químico na dinâmica do desenvolvimento de lesão da doença cárie (Benelli et al., 1993) e/ou na ação antimicrobiana interferindo na produção de ácido inibindo o crescimento bacteriano (Friedl et al., 1997). Para avaliar o comportamento do flúor como um dos componentes básico materiais restauradores no controle da doença cárie é de extrema importância que ocorra a ionização, isto é, a liberação na forma de íon desse elemento para sua participação no mecanismo de remineralização e efeito antibacteriano (Martins et al., 1991; Carvalho e Cury, 1999). Por outro lado, o valor de $\mathrm{pH}$ dos materiais deve chegar a níveis baixos para que haja a acidificação favorecendo a ionização e seja, portanto potencializada a sua ação reduzindo a progressão da lesão de cárie. (Forsten, 1991; Modesto et al., 1997, Fraga et al., 2002).

$\mathrm{O}$ trabalho teve como objetivo avaliar o $\mathrm{pH}$ do meio aquoso de imersão de alguns materiais restauradores com flúor na composição durante a reação de presa e hidratação.

\section{Material e método}

Foram testados nove materiais restauradores cujas marcas comerciais e respectivos fabricantes (tabela1), para avaliar a capacidade de alteração do $\mathrm{pH}$ do meio aquoso em quatro períodos: 3 minutos, 4 horas, 72 horas e 7 dias. 
Tabela 1 - Materiais utilizados no estudo.

\begin{tabular}{l|l|l}
\hline Material & Fabricante & Classificação do Material \\
\hline Vidrion R (VI) & SS White, Brasil & Ionômero de vidro \\
\hline Ionofil (IO) & Voco & Ionômero de vidro \\
\hline Ketac Molar (KM) & 3M Espe, USA & Ionômero de vidro \\
\hline Freedom (FR) & SDI & Resina composta modificada por poliácido \\
\hline Compoglass (CO) & Vivadent, Liechterstein & Resina composta modificada por poliácido \\
\hline Vitremer (VT) & 3M, USA & Ionômero de vidro modificado por resina \\
\hline Fill Magic Condensável & Vigodent & Resina Composta \\
(FM) & & \\
\hline Charisma F (CHA) & Kulzer & Resina Composta \\
\hline
\end{tabular}

Para cada período testado, foram fabricados três corpos de prova de cada material, seguindo as recomendações do fabricante e construídos a partir de matrizes circulares em teflon bipartidas com um orifício central, também circular de $6 \mathrm{~mm}$ de diâmetro e $3 \mathrm{~mm}$ altura, mantida e envolvida por uma matriz de aço. Para a obtenção dos corpos de prova do cimento de ionômero de vidro e ionômero de vidro modificado por resina, após a manipulação dos materiais, estes foram inseridos na matriz que estava disposta em uma placa de vidro, adaptou-se uma tira de poliéster e com outra placa de vidro exercendo pressão manual para extravasamento do excesso, deixando, desta forma, ambas as superfícies lisas e regulares. Os corpos de prova preparados de cimento de ionômero de vidro eram mantidos na mesma temperatura até o processo de reação de endurecimento inicial, sendo que, para o ionômero de vidro modificado por resina após este procedimento era aplicada luz fotopolimerizável em cada face por 40 segundos.

Para obtenção dos corpos de prova de resina composta e resina composta modificada por poliácido (Compômero), seguindo a recomendação do fabricante o material foi inserido no orifício da matriz com o auxilio de uma espátula seguida da fita de poliéster e pressionada pela placa de vidro para evitar bolhas e extravasar o excesso do material. Os materiais receberam 40 segundos de aplicação de luz fotopolimerizável em cada face.
Os corpos de prova após a manipulação foram armazenados em 1,0 ml de água destilada (pH 6,7), em tubos de ensaio individualizado devidamente identificados para cada material. Os tubos foram agitados por 10 segundos com o auxílio de um agitador de tubo mecânico de alta freqüência (Marconi equipamentos para laboratórios LTDA - MA562) para facilitar a liberação de íons. Foram mensurados os valores de $\mathrm{pH}$ em meio aquoso (pH neutro) com aparelho analisador digital de íons Orion modelo EA-940 (Orion Resesearch, Inc.) nos tempos de 3 minutos, 4 horas, 72 horas e 7 dias correspondentes à reação de presa e hidratação dos materiais utilizados. Para a avaliação dos resultados foi calculada a média aritmética das repetições dos valores obtidos em meio aquoso individualmente e correspondentes aos grupos de materiais utilizados. Para estatística foi aplicados a Análise de Variância (Anova) e o teste Tukey ao nível de 5\% de significância.

\section{Resultado}

Após a obtenção das médias dos valores de pH em meio aquoso dos materiais estudados, a Análise de Variância demonstrou diferença estatística entre os períodos, foi aplicado teste Tukey $(1,084)$ para mostrar as diferenças nos períodos. 
Foi observado que todos os cimentos de ionômero de vidro convencionais (Vidrion R, Ionofil, Ketac Molar) e o ionômero de vidro modificado por resina (Vitremer), não mostraram diferenças significativas entre si, porém foram significantes nos períodos de $3 \mathrm{mi}$ nutos e 4 horas quando comparados com os outros materiais.

Após 4 horas de hidratação, a resina composta com poliácido, Compoglass (CO) provocou uma marcante queda de $\mathrm{pH}$, mantendo-se em queda nos demais períodos. Para o Freedom (FR), teve redução com manutenção do $\mathrm{pH}$ e as resinas (Fill Magic, Charisma F) queda do $\mathrm{pH}$, mas todos não significantes em todos os períodos.

Tabela 2 - Média de pH em meio aquoso de imersão dos vários materiais, nos diferentes períodos estudados.

\begin{tabular}{c|c|c|c|c}
\hline Período & \multirow{3}{*}{ minutos } & $\mathbf{4}$ horas & $\mathbf{7 2}$ horas & $\mathbf{7}$ dias \\
\hline VI & 3,88 & 4,32 & 5,05 & 5,47 \\
\hline IO & 4,24 & 4,60 & 5,12 & 5,46 \\
\hline KM & 3,36 & 4,46 & 5,01 & 5,31 \\
\hline FR & 6,95 & 6,68 & 5,84 & 5,97 \\
\hline CO & 7,52 & 5,90 & 5,15 & 5,08 \\
\hline VT & 4,33 & 4,62 & 4,58 & 5,19 \\
\hline FM & 6,35 & 6,29 & 5,92 & 6,05 \\
\hline CHA & 6,33 & 6,35 & 5,90 & 5,94 \\
\hline
\end{tabular}

\section{Discussão}

A incorporação de fluoreto na composição dos diferentes materiais é parte da importância que o flúor exerce na prevenção e no controle da progressão da doença cárie. Estes materiais pela ação do flúor podem agir interferindo no processo de desmineralização e/ou propiciar algum potencial antibacteriano sobre a flora microbiana (Martins et al., 1991; Carvalho e Cury, 1999). Assim, a presença deste íon em lesões de cárie pode alterar o metabolismo dos estreptococos mutans
(Loesche, 1993) e estabilizar a microbiota com respeito aos carboidratos fermentáveis (March, 1994).

Para que este efeito aconteça há necessidade que o veículo tenha características ácidas para propiciar acidificação do meio e ocorrer a ação antibacteriana (Loesche, 1986; Fraga et al., 1996). Grande parte das bactérias cariogênicas é reduzida por não suportar um $\mathrm{pH}$ inferior a quatro quando são expostas ações químicas de substâncias (Meiers e Miller, 1996). Para que possamos nos beneficiar das substâncias liberadas dos materiais odontológicos como o flúor, é importante conhecer a sua composição, reação de presa, o que favorece a determinação do mecanismo ação (Arends e Christofferen, 1990; Rawls, 1991).

Os dados obtidos no presente estudo revelaram que houve diferença nos valores de $\mathrm{pH}$ em meio aquoso entre os materiais restauradores estudados em razão das diferentes composições, portanto com diferentes formas de reações de presa. Fraga et al. (2001), após mensurar os valores de $\mathrm{pH}$ de seis materiais restauradores contendo flúor em sua composição relataram quanto a acidificação que: os materiais somente fotopolimerizáveis não o alteravam, o compômero mostrou tendência após quatro horas de hidratação e os ionômeros convencionais e reforçados apresentaram acidificação da solução.

Os materiais Vidrion R, Ionofil, Ketac Molar e Vitremer avaliados no estudo, não apresentaram diferenças estatísticas embora, a acidificação do meio foi significante nos dois primeiros períodos [(VI) 3,88, 4,32; (IO) 4,24, 4,60; (KM) 3,36, 4,46; (VT) 4,33, 4,62)]. Estes dados estão de acordo com os estudos de Tobias et al.(1985), onde relatam que a acidificação exercida pelos cimentos de ionômero de vidro ocorre devido à reação de geleificação decorrente da reação ácido-base. Este fato facilita a ionização e a penetração do íon flúor no citoplasma bacteriano, diminuindo seu metabolismo e selecionando uma microbiota menos cariogênica. Aacidificação que favorece a ionização deste composto também pode inibir o metabolismo dos peptidioglicano, a enzima ATPase, fosfatase, enolase e o transporte de carboidratos (Hamilton, 1990). Ciccone et al. (2004), com o objetivo de avaliar "in vitro" a capacidade antibacteriana de diferentes materiais restauradores sobre Streptococcus mutans, Staphylococcusaureus, Micrococcus luteus e Streptococcus sobrinus, mos- 
traram que o Vidrion R apresentou a maior capacidade antimicrobiana, justificada pelas diferentes composições apresentadas pelos cimentos de ionômero de vidro. Com relação aos valores de $\mathrm{pH}$, o ionômero de vidro Ketac Molar $(3,36)$ encontrado na pesquisa foi o material que apresentou menores valores após a manipulação. Tal fato pode estar ligado ao aumento da viscosidade pela proporção pó-líquido, diminuição do tempo de presa característica que pode alterar a sua composição e a capacidade e liberação dos fluoretos (Araujo et al., 1996).

Por apresentar componentes semelhantes ao cimento de ionômero convencional a incorporação de monômero resinoso ao ionômero de vidro (Vitremer) manteve a acidificação do meio em ordem decrescente, nos períodos estudados. Fraga et al. (1996), avaliaram a capacidade inibitória deste material sobre os microrganismos bucais, notando que após a reação de presa ocorre uma diminuição progressiva da atividade bacteriana que coincide com a de liberação do flúor.

As resinas compostas modificada por poliácidos (Compômero) Compoglass e o Freedom comportaram-se de forma diferente, sendo que no período de quatro horas de hidratação o Compoglass $(5,90)$ apresentou marcante queda de $\mathrm{pH}$ do meio, que era de 7,52 para 5,90 mantendo destes valores baixos nos outros períodos e o Freedom $(6,69)$ mostrou uma leve queda do $\mathrm{pH}$ a partir de quatro horas de hidratação, entretanto apresentando sua maior queda no período de 72 horas $(5,84)$. Este diferente valor de $\mathrm{pH}$ no meio aquoso pode estar relacionado a composição do material que pode interferir na capacidade de liberação de fluoreto. Para Vermeersch et al. (2001) a reação de geleificação ácido-base e composição química do material podem influenciar a liberação dos íons fluoreto. As resinas compostas testadas (Fill Magic e Charisma F), não foram capazes de acidificar o meio aquoso.

Dado os resultados obtidos acreditamos que novos estudos devam ser realizados para avaliar o comportamento destes materiais que apresentam flúor em sua composição para melhor qualificar suas propriedades oferecendo benefício biológico e restaurador.

\section{Conclusões}

Após a interpretação dos dados foi possível concluir que:

1. Materiais que apresentam reação ácido-base (Vidrion R, Ionofil, Ketac Molar e Vitremer) acidificaram o meio aquoso de imersão priorizando os períodos iniciais.

2. Os compômeros (Compoglass e Freedom) apresentaram tendência a redução do $\mathrm{pH}$ no meio aquoso nos períodos de 4 e 72 horas após hidratação.

3. As resinas compostas (Fill Magic, Charisma F) não provocam redução de $\mathrm{pH}$.

\section{REFERÊNCIAS}

1. ARAUJO, F.B.; GARCIA-GODOY, F.; CURY, J.A.; CONCEIÇÃO, E.N. Fluoride realease from fluoride-containing materials. Oper Dent, v.21, n.5, p.185-190, 1996.

2. ARENDS, J. e CHIRISTOFFERSEN, J. Nature and role of loosely bound fluoride in dental caries. J Dent Res, v.69 Spec, n: 601-5; discussion 634-6, 1990.

3. BENELLI,E.M.; SERRA, M.C.; RODRIGUES, A.L. Jr.; CURY, J.A. In situ anticariogenic potential of glass ionomer cement. Caries Res, v.27, n.4, p.280-284, 1993.

4. CARVALHO, A.S. e CURY, J. A. Fluoride release from some dental materials in different solutions. Oper Dent, v.24, n.1, p.14-9, 1999.

5. CICCONE, J.C.; VERRI, M.P.; NAVARRO, M.F.L.; SALVADOR, S.L.; PALMA-DIBB, R.G. Avaliação in vitro do potencial antimicrobiano de diferentes materiais restauradores. Mat Res, v.7, n.2, p.231-234, 2004.

6. FORSS, H. e SEPPÃ, L. Prevention of enamel demineralization adjacent to glass ionomer filling materials. Scand J Dent Res, v.98, n.2, p.173-178, 1990.

7. FORSTEN, L. Fluoride release and uptake by glass ionomer. Scand J Dent Res, v.99, n.3, p.2451-245, 1991.

8. FRAGA, R.C.; SIQUEIRA Jr, J.F.; UZEDA, M. In vitro evaluation of antibacterial effects of photo-cured glass-ionomer linear and bonding agents during setting. J Prosthet Dent, v.73, n.5, p.483-486, 1996.

9. FRAGA, R.C.; MARTINS, L.R.M.; SIQUEIRA Jr, J.F.; 
FRAGA, L.R.L. Variação de pH em reação de presa de materiais restauradores fluoretados. Rev Bras Odont, v.59, n.5, p.415417, 2002.

10. FRIEDL, K.H.; SCHMALZ, G.; HILLER, K.A.; SHAMS, M. Resin-modified glass ionomer cements: fluoride release and influence on streptococcus mutans growth. Eur J Oral Sci, v.105, n.1, p.1770-1774, 1987.

11. HAMILTON, J.R. Biochemical effects of fluoride on oral bacteria. J Dent Res, v.69, n.2, p.660-667, 1990. [Special Issue].

12. LOESCHE, W.J. Role of Streptococcus mutans in human dental decay. Microbial Rev, v.50, n.4, p.353-80, 1986.

13. LOESCHE, W.J. Bacterial mediators in periodontal disease. Clin Infect Dis, v.16, n.4, p.203-10, 1993.

14. MARCH, P. Effect of fluorides on bacterial metabolism. In: BOWEN, W.H. Relative efficacy of sodium fluoride and sodium monofluorphosphate as anticaries agents in dentifrices. London: Royal Society of Medicine, 1994. p.9-13.

15. MARTINS, L.R.M.; SERRA, M.C.; FRANCISCHONE, C.E. Fluoride release a glass ionomer cement subject to demineralization.
Remineralization cycles. J Dent Res. v.70, n.4, p.638, 1991.

16. MEIERS, J.C.; MILLER, G.A. Antibacterial activity of dentin bonding systems, resin-modified glass ionomers, and polyacidmodified composite resins. Oper Dent, v.21, n.6, p.257-64, 1996.

17. MODESTO, A.; CHEVITARESE, O.; CURY, J.A.; VIEIRA, A.R. Variglass fluoride release and uptake by an adjacent tooth. Am J Dent, v.10, n.3, p.123-127, 1997.

18. RAWLS, H.R. Preventive dental materials sustained delivery of fluoride and other therapeutic agents. Adv Dent Res, v.5, n.12, p.50-5, 1991.

19. SWARTZ, M.L.; PHILLIPS, R.W.; CLARK, H.E. Long-term fluoride release from glass ionomer cements. J Dent Res, v.63, n.2, p.158-160, 1984.

20. TOBIAS, R.S.; BROWNE, R.M.; WILSON, C.A. Antibacterial activity of dental restorative materials. Int Endod J, v.18, n.3, p.161-71, 1985.

21. VERMEERSCH, G.; LELOUP, G.; VREVEN, D.F. Fluoride release from glass-ionomer cements, compomers and resin composites. J Oral Rehabil, v.28, n.1, p.26-32, 2001. 